\title{
Use of Seton in Management of High Variety of Anal Fistula
}

\author{
$*$ M Noor ${ }^{1}, \mathrm{~S}$ Abbasi ${ }^{2}$
}

\begin{abstract}
Background: Anal fistula is an abnormal communicative small channel that has an internal opening and an external opening and connected by the primary track. Our study evaluate the effectiveness of seton in high variety anal fistula.

Objectives: Evaluation the efficacy and safety of seton as surgical management of high anal fistula.

Methods: This is a prospective study done on 57 patients in BIRDEM hospital and some other clinic of Dhaka city in 3 years period with high variety of anal fistula which is above the dentate line and were treated with seton .Outcome measured during follow up period were- successfully healed, recurrence, incontinence, percentage of complications and patients satisfaction.

Result: Among 57 patients mean age was $38.2+6.8$ years. Overall outcome of the patients showed-fistula completely healed in 51 patients, incontinence occurred in 2 patients and recurrence occurred in 4 patients.

Conclusion: Seton is relatively safe, effective and low cost for the management of high anal fistula with low rate of incontinence. It can therefore, be recommended as the standard of treatment for high variety fistula in ano.
\end{abstract}

Key Words: Anal canal, fistula, surgery, seton

\section{Introduction}

Anal fistula is common and debilitating perineal condition. Usually characterized by severe pain and discharge. They arise following infection near the anal canal, or as a primary event from an abscess ${ }^{1}$. It is an abnormal connection between two epithelialized surfaces, and is lined with granulation tissue. Perineal fistula is between the intestine and the perineal skin. Fistula-in-ano is one of the commonly encountered surgical problems with prevalence of 1.2 to $2.8 / 10,000$. In approximately $80 \%$ of cases, anal fistulae are secondary to abscesses arising from infected anal glands (cryptogenic) $^{2}$. Infection in the anal gland may result in an abscess between the internal and external sphincters, which in turn can spread to other parts of the perianal region. Infection can then track in many directions from this focus in the intersphincteric plane ${ }^{3}$. When the track reaches the skin or another epithelialized surface then a fistula is formed. Anal fistula were classified on the basis of its relationship to the sphincters. The definition of high or low describes the height of the track as it traverses the sphincter muscles and not the position of the internal opening which is almost without exception at the dentate line. More accurately according to parks classification fistula in ano can

\footnotetext{
${ }^{1}$ Dr. Mohammad Noor-A-Alam; Associate Professor and Unit head

Dept of Surgery, BIRDEM and Ibrahim Medical College

${ }^{2}$ Dr.Sharmin Abbasi, AssistantProfessor, Dept of Obstetrics and Gynecology

Anwer Khan Modern Medical College Hospital

*Corresponding Author
}

Date of submission: 08.10.2016, Date of acceptance: 23.01.2017 
be inter sphincteric, transsphincteric, Suprasphinteric and extrasphincteric ${ }^{4}$.

The goals of treatment are draining infection, eradicating the fistulous tract, and avoiding persistent or recurrent disease while preserving anal sphincter function. Treatment options of anal fistula include fistulotomy, seton placement, endorectal advancement flap, dermal island flap, fistula plug, fibrin injection and ligation of the intersphincteric fistula tract. ${ }^{5}$ Surgical treatment of anal fistula depends on the amount of sphincter involvement and internal and external anal sphincters preservation for continence maintenance ${ }^{6}$.

Seton is any string-like material which when tied through the fistula tract causes an inflammatory reaction which stimulates fibrosis that fixes and prevents retraction of the sphincter continuity when it is divided. In this way, it maintains sphincter continuity during cutting process ${ }^{7}$. Different types of setons are used for this purpose like silastic tube, silk, linen, braided silk, rubber band, braided polyester, vascular loop, polypropylene, nylon, cable tie, and so forth. The reported incontinence and recurrence rate ranges from $0 \%$ to $62 \%$ and from $0 \%$ to $16 \%$, respectively, with different materials used as seton. The Proline seton is very cheap, easily inserted, and provides convenient tightening in a clinic setting without need of analgesia ${ }^{8}$. This prospective study done to determine the completely healed, incontinence and recurrence rate of seton in our Hospital.

\section{Materials and Method}

This is a prospective study of patients with high anal fistula, above the dentate line, treated with proline seton over 3 years period from February 2014February 2017, in BIRDEM hospital and some others clinic in Dhaka city. Patients with existing preoperative incontinence, inflammatory bowel disease, intestinal tuberculosis, malignancies, anorectal tumor were excluded.

After spinal anesthesia the rectum and anal canal were examined again, the fistulous tract was gently probed with a small, flexible metal probe. The seton was created by proline $1 / 0$. The portion of the tract outside the sphincters was opened and curetted. The skin overlying the fistulous tract was incised. This seton was then tied over itself on the sphincter. Retightening of the cutting seton was done every 2 weeks postoperatively which helps in fibrosis and gradual division of the sphincter, thus eliminating the fistula while maintaining continuity of the sphincter. Postoperatively gentle cleaning of the anal region with warm water after each bowel movement was advised. The patients were informed in detail about the presence of the prosthesis, and they were warned about the possible serous discharge that would continue until the seton dropped and the wound healed. Postoperatively, the patients were re examined at weekly intervals and monthly after drop of seton and encouraged to inform whenever they suspected a problem like recurrence, incontinence and whenever they recognized that the seton dropped. Follow-up for fistula recurrence, incontinence, and degree of satisfaction was done for at least 6 months postoperatively.

Data was analyzed with SPSS version 17. Continuous variables were analyzed as means \pm SD; where as categorical variables were analyzed as proportions and percentages. Risk factors of recurrence were analyzed with Chi square test value $<.05$ is significant.

\section{Result}

We operated on 57 patients of fistula-in-ano with seton during Februry 2014and february 2017, with mean age of the patients were $38.2 \pm 6.8$ years. 46 $(80.7 \%)$ were males, and $11(19.3 \%)$ were female. $51(89.5 \%)$ patients did not have any prior history of perianal problem. The transsphincteric-type fistula was the most frequent being seen in 39 cases $(68.4 \%)$, and the horseshoe type was found in 5 cases $(8.8 \%) .23$ patients had a fistula concomitant with abscess and the number of patients having a fistula without abscess was 34. Among the 23 fistulous abscess cases, the most common was the transsphincteric type with ischiorectal abscess. 52(91.2\%) patients had no previous history of surgery for fistula-in-ano, rest of the patients were presented with recurrent fistula. Fistula tract was traced and delineated in all the cases. 
The seton was tightened with a median of six times (3-12times range). Most of the patients tolerated the tightening session well with no or minimal need of analgesia. Complete healing was achieved in 1 $0.12 \pm 3.75$ weeks. All the patients were followed up for a minimum period of 6 months or till healing. During the analysis of overall outcome 2 patients reported incontinence. Recurrence was found in $4(7 \%)$ patients. Among patients with recurrence, 3 were treated with seton alone and 1 with combined operation. One patient got the seton removed prematurely owing to unbearable discomfort. None of the patients had bleeding, wound infection, premature dislodgement, or slippage of the seton.

Table 1: Baseline Variables of the patient

\begin{tabular}{lc}
\hline Variables & Value (\%) \\
\hline Age & $38.2 \pm 6.8$ years \\
Sex & \\
Male & $46(80.7 \%)$ \\
Female & $11(19.3 \%)$ \\
Symptoms & \\
Recurrent painful perineal & $34(59.6 \%)$ \\
Swelling with discharge & $17(29.8 \%)$ \\
Painless perineal Discharge & $6(10.5 \%)$ \\
Passage of air through fistula opening & \\
Past History of perineal problem & \\
No & $51(89.5 \%)$ \\
Yes & $6(10.5 \%)$ \\
Past History of fistula surgery & \\
No & $52(91.2 \%)$ \\
Yes & $5(8.8 \%)$ \\
Diabetes & \\
Yes & $47(82.5 \%)$ \\
No & $10(17.5 \%)$ \\
\hline
\end{tabular}

Table-2: Distribution of types of fistula

\begin{tabular}{lc}
\hline Types of Fistula & Value \\
\hline Primary & $48(84.2 \%)$ \\
Recurrent & $9(15.8 \%)$ \\
Intersphincteric & $13(22.8 \%)$ \\
Transsphincteric & $39(68.4 \%)$ \\
Horse shoe & $5(8.8 \%)$ \\
\hline
\end{tabular}

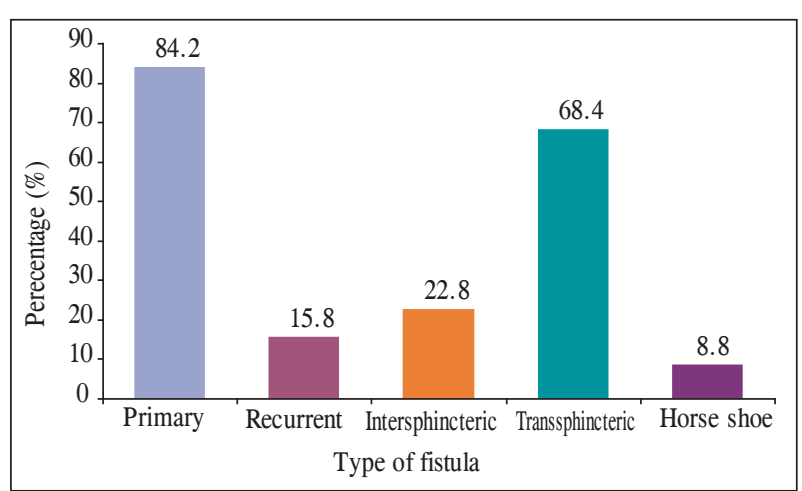

Fig. 1: Type of fistula among patients

Table 3: Overall outcome of the patients

\begin{tabular}{lc}
\hline TVariables & Value \\
\hline Completely healed & $51(89.5 \%)$ \\
Recurrence & $4(7.0 \%)$ \\
Incontinence & $2(3.5 \%)$ \\
\hline
\end{tabular}

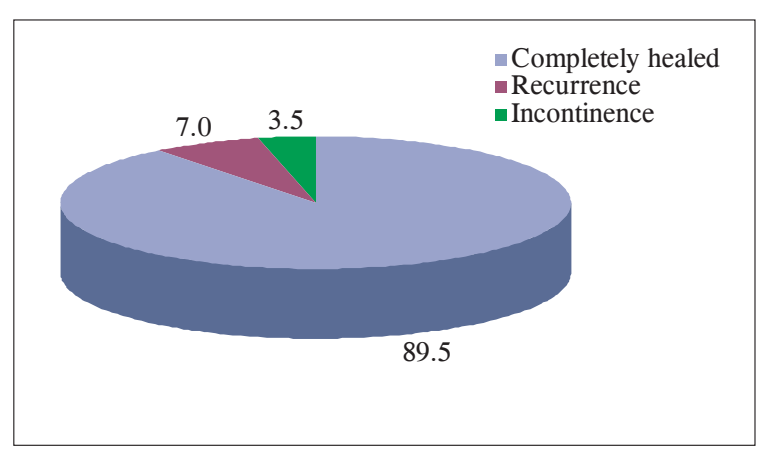

Fig. 2: Overall outcome of the patients

Table 4: Risk factors for recurrence

\begin{tabular}{lccc}
\hline Characteristic & Recurrence & Recurrence & P value \\
\hline DM ( 47) & 1 & 1 & $0.641 \mathrm{~ns}$ \\
Previous surgery (5) & 1 & 1 & $0.001 \mathrm{~s}$ \\
Type of fistula & & & \\
Primary (48) & 0 & 0 & $0.019 \mathrm{~s}$ \\
Recurrent (9) & 1 & 1 & \\
& & & \\
\hline
\end{tabular}

$P$ value reached from Chi-square test, $s=$ significant, $n s=$ not significant 
Table 5: Wexner's score for fecal incontinence.

\begin{tabular}{lccccc}
\hline Characteristic & Never & Rarely & Some times & Usually & Always \\
\hline Flatus & 0 & 1 & 2 & 3 & 4 \\
Liquid stool & 0 & 1 & 2 & 3 & 4 \\
Solid stool & 0 & 1 & 2 & 3 & 4 \\
Wears pad & 0 & 1 & 2 & 3 & 4 \\
Alteration in lifestyle & 0 & 1 & 2 & 3 & 4 \\
\hline
\end{tabular}

Range (0-20); $0=$ normal continence and $20=$ maximum incontinence with maximum disturbance of life style.

\section{Discussion}

In this study among 57 patients $89.5 \%$ were completely healed $3.5 \%$ had incontinence and $7 \%$ recurrence rate. The data was collected prospectively from patients. The data on continence was determined by validated Wexner's score in all the patients with complete follow up, which includes incontinence of feces as well as flatus. All the procedures were done by a single surgeon to eliminate the bias. It is a single line study with no comparison group. The majority of the patients were males; this unintentional selection bias was the result of cultural norms in our country as the females prefer to be managed by female surgeons ${ }^{9}$.

Same seton materials has been. But whatever the material is, recurrence and incontinence rate is mainly dependent on expertise and judgment of the surgeon. So, there are other factors that need to be considered during the selection of the seton. The seton should be durable, cheap, nontoxic/non allergic, technically easy to tie even and allows to tight repeatedly without causing pain and without anesthesia ${ }^{10}$. With these properties, prolone stands out above all, which guides the operator to adequately tight it by just slipping one end without any need of further retraction. Hence, the tightening is gradual and controlled. After tightening, none of the patients had unbearable pain for more than few minutes; this is attributed to the precise and controlled tightening achieved by prolene as well as the fact that we did not tighten it until found loose. None of the patients reported any difficulty in walking or carrying out routine activities. The prolene once engaged, is self locking and is retained in place by the tissues within the loop. Free movement and irritation of the gluteal tissues was prevented by a wad of gauze on either side of the free end of the seton.

Prolene has been used previously, with similar results as in our study. Gurer et $\mathrm{al}^{11}$. Found $2 \%$ recurrence and incontinence in 7 patients treated with seton, with mean healing time of 37.04 days and $8 \%$ complication rate.Vatansev et $\mathrm{al}^{12}$. Presented a series of 32 patients treated with cable tie and reported no recurrence, $15.6 \%$ incontinence rate, and mean healing time of 53 days. We conducted this study on 57 patients and incontinence found in 2 patients and complications with low recurrence proportion of $1.4 \%$. Prolene seton does not suffer the problems of loosening as in elastic tie. Other techniques of treatment have been reported including fibrin glue, Ligation of Intersphincteric fistula tract and collagen plug. Met analysis of trials on fibrin glue did not report any statistically significant difference over other techniques for recurrence or incontinence ${ }^{13}$ moreover, it is too expensive to be used in a low income country-the cost of fibrin glue equals the cost of entire day care procedure of seton placement. Early experience of LIFT is also promising and sounds good alternative ${ }^{14}$ however, besides a steep learning curve, it needs technical expertise especially for complex fistulae.

The factors implicated in fistula recurrence include the complexity and level of the fistula, the presence or absence of a horseshoe extension, the degree of laterality of the external opening, failure by the surgeon to identify the internal opening at initial surgery, and the overall surgical experience of the operator in complicated proctologic practice ${ }^{15}$. In our study, we were able to identify the internal opening in all the patients without radiological investigations, and if we correlate this with the low recurrence rate, we can conclude that the most important factor is the surgeon's experience and judgment ${ }^{16}$. Although this seems to be a subjective decision, but it is pragmatic and cost effective in low-income country like ours. Looking into the literature, a wide range of incontinence rates is reported after cutting seton treatment, and Ritchie et al. ${ }^{17}$ have concluded that there was no relationship between incontinence and the frequency of tightening, type of seton, or classification of 
fistula. ${ }^{18}$ Hence, we further reinforce the importance of surgeon's experience and the use of a seton having additive qualities as stated above.

\section{Conclusion}

The proline seton is safe, precise, and cost-effective option for the treatment of high fistula-in-ano. We, therefore, recommend it to treating high fistulae-inano requiring the placement of a seton. It does not carry the disadvantage of repeated anesthesia and visits to the operating theater and reduces the morbidity, inconvenience, and cost to the patient. But it should be in expert surgeon's hand.

Conflict of interest: We have no conflict of interest.

\section{References}

1. Schouten WR, van Vroonhoven TJ: Primary partial internal sphincterectomy in the treatment of anorectal abscess. Neth J Surg. 2013;39:43-45.

2. Ritchie RD, Sackier JM, Hodde JP. Incontinence rates after cutting seton treatment for anal fistula. Colorectal Dis. 2009;11:564-571.

3. Cox SW, Senagore AJ, Luchtefeld MA. Outcome after incision and drainage with fistulotomy for ischiorectal abscess. Am Surg. 1997;63:686-689.

4. Enck P, Bielefeldt K, Rathmann W, Epidemiology of faecal incontinence in selected patient groups. Int $\mathrm{J}$ Colorectal Dis. 1999;6:143-146.

5. Parks AG, Stitz RW. The treatment of high fistula-inano. Dis Colon Rectum. 1996;19: 487-499.

6. Thomson JP, Ross AH. Can the external anal sphincter be preserved in the treatment of transsphincteric fistula-in-ano? Int J Colorectal Dis. 1998;4:247-250.

7. Scoma JA, Salvati EP, Rubin RJ. Incidence of fistulas subsequent to anal abscesses. Dis Colon Rectum. 1974; 17:357-359

8. Eitan A, Koliada M, Bickel A. The use of the loose seton technique as a definitive treatment for recurrent and persistent high trans-sphincteric anal fistulas: a long-term outcome. J Gastrointest Surg. 2009; 13: 1116-1119.
9. C. Zanotti, C. Martinez-Puente, "An assessment of the incidence of fistula-in-ano in four countries of the European Union," International Journal of Colorectal Disease, vol. 22, no. 12, pp. 1459-1462, 2007.

10. A. G. Parks, P. H. Gordon, and J. D. Hardcastle, "A classification of fistula in ano," British Journal of Surgery, vol. 63, no. 1, pp. 1-12, 1976.

11. I. J. Kodner, A. Mazor, E. I. Shemesh et al., "Endorectal advancement flap repair of rectovaginal and other complicated anorectal fistulas," Surgery, vol. 114, no. 4, pp. 682-690, 1993.

12 N. Mizrahi, S. D. Wexner, O. Zmora et al., "Endorectal advancement flap: are there predictors of failure?" Diseases of the Colon and Rectum, vol. 45, no. 12, pp. 1616-1621, 2002.

13. F. Seow-Choen and R. J. Nicholls, "Anal fistula," British Journal of Surgery, vol. 79, no. 3, pp. 197-205, 1992.

14. R. K. Pearl, J. R. Andrews, C. P. Orsay et al., "Role of the seton in the management of anorectal fistulas," Diseases of the Colon and Rectum, vol. 36, no. 6, pp. 573-579, 1993.

15. R. D. Ritchie, J. M. Sackier, and J. P. Hodde, "Incontinence rates after cutting seton treatment for anal fistula," Colorectal Disease, vol. 11, no. 6, pp. 564-571, 2009.

16. M. Vial, D. Parés, M. Pera, and L. Grande, "Faecal incontinence after seton treatment for anal fistulae with and without surgical division of internal anal sphincter: a systematic review," Colorectal Disease, vol. 12, no. 3, pp. 172-178, 2010.

17. C. J. Vaizey, E. Carapeti, J. A. Cahill, and M. A. Kamm, "Prospective comparison of faecal incontinence grading systems," Gut, vol. 44, no. 1, pp. 77-80, 1999.

18. A. Gurer, N. Ozlem, A. K. Gokakin, M. Ozdogan, H. Kulacoglu, and R. Aydin, "A novel material in seton treatment of fistula-in-ano," American Journal of Surgery, vol. 193, no. 6, pp. 794-796, 2007. 